\title{
Risk factors of paediatric community-acquired pneumonia
}

\section{To the Editors:}

The article by TEEPE et al. [1] recently published in the European Respiratory Journal is an interesting paper on the risk factors of community-acquired pneumonia (CAP) in children and adults in a primary-care setting. The study population consisted of 156 young adults and 107 children (aged <15 yrs) suffering from CAP, and three controls were selected for each case from the same age group. The criteria for the diagnosis of CAP were either a radiological confirmation or the presence of at least three out of six defined respiratory signs/symptoms. Focusing on the paediatric age only, the multivariate analysis showed that lower age (OR 0.88), asthma (OR 3.57) and previous upper respiratory tract infections (OR 1.80 for one to two episodes and 2.46 for more than three episodes) were independently associated with CAP in children. Several aspects of the study by TEEPE et al. [1] should be underlined.

First, as conveniently evidenced by the authors, not all the diagnosis of CAP were radiologically confirmed, thus probably biasing the results. Moreover, two out of the six allowable signs/symptoms for a clinical diagnosis of pneumonia were more easily applicable in adult than in paediatric patients; these were local chest pain on deep inhalation and increased vocal resonance. Symptoms described in adults with bacterial pneumonia may be noted in older children but are rarely observed in infants and young children [2]. On the contrary, abdominal pain, which is common in lower lobe pneumonia [2] and tachypnea, which, even if recently criticised, remains the most consistent clinical manifestation of paediatric pneumonia above all in developing countries [2, 3], are not mentioned. Any aetiological analysis has been performed in the study material and exclusion criteria have not been clearly stated. In fact, children who suffer from underlying chronic disease (e.g. sickle cell disease, bronchopulmonary dysplasia, gastro-oesophageal reflux, asthma, cystic fibrosis, congenital heart diseases, immunodeficiency syndromes, neuromuscular diseases and seizure disorders) are at higher risk for acquiring pneumonia [4]. However, among the inclusion criteria the authors included non-Western minorities [1] but not the definite risk factors for CAP (among which are malnutrition, low birth weight and measles immunisation) typical in developing countries and which explain the higher incidence found in these countries [5]. In developing countries pneumonia is not only more common than in Europe and North America, but is also more severe and characterised by a higher mortality rate in the paediatric population [5].

Secondly, the authors found that lower age is as an independent determinant of CAP in the paediatric population [1], but this practical aspect has probably not been stressed and discussed enough. Even if the sample size was limited, the data of TEEPE et al. [1] are useful to remark that incidence of pneumonia decreases when children grow up. The incidence of CAP in Finnish children studied during 1981-1982 was 36 out of 1,000 per yr in children aged $<5$ yrs and $\sim 16$ out of 1,000 per yr in the 5-14 yr age group. A strong male prevalence was found below 5 yrs of age (11.2 out of 1,000 among males and 5.7 out of 1,000 among females) [6], contrary to the figure found by TEEPE et al. [1]. These estimates were similar in the American paediatric population (1,483 CAP episodes studied between 1964 and 1975): 40 cases out of 1,000 per yr in the 6 months to 5 yrs age group; 22 cases out of 1,000 per yr in children aged 5-9 yrs; 11 cases out of 1,000 per yr in children aged 9-12 yrs; and seven cases out of 1,000 per yr in children aged 12-15 yrs [7].

Finally, the authors concluded that their study is the first to explore the determinants of CAP in children and young adults in primary care [1]. Actually, the first case-control study on risk factors for paediatric CAP in developed countries is a Finnish study of 201 patients and 250 healthy controls in which HEISKANEN-Kosma et al. [8] found that children who are prone to recurrent respiratory infections (RRIs), wheezing and acute otitis media are also prone to pneumonia. In this study by HEISKANEN-KOSMA et al. [8] the risk factors for CAP in children aged $<5$ yrs were RRIs during the previous 12 months (OR 5.5) and a history of wheezing episodes (OR 5.3) or otitis media treated by tympanocentesis in the first 2 yrs of life (OR 3.6). In the 5-15 yrs age group, risk factors for CAP were RRIs in the last year (OR 3.0) and a positive history for wheezing episodes (OR 2.1) [8]. Significantly, all these findings are in line with the study of TEEPE et al. [1].

In conclusion, more prospective case-control studies on risk factors for CAP in children are needed to allow us to plan the best prevention strategies. Such studies should cover more epidemiological seasons and they should be based on a proper sample size, radiologically confirmed diagnosis of pneumonia and an extensive microbiological work-up in both hospitalised and ambulatory patients of all paediatric age groups.

\section{Don}

Paediatric Care Unit, Sant' Antonio General Hospital, San Daniele del Friuli, Udine, Italy.

Correspondence: M. Don, Paediatric Care Unit, Sant' Antonio General Hospital, Viale Trento Trieste 33, 33038 San Daniele del Friuli, Udine, Italy. E-mail: max.don@libero.it

Statement of Interest: None declared. 


\section{REFERENCES}

1 Teepe J, Grigoryan L, Verheij TJ. Determinants of communityacquired pneumonia in children and young adults in primary care. Eur Respir J 2010; 35: 1113-1117.

2 Sectish TC, Prober CG. Pneumonia. In: Kliegman RM, Behrman RE, Jenson HB, et al., eds. Nelson Textbook of Pediatrics. 18th Edn. Philadelphia, Elsevier Saunders, 2007; pp. 1795-1800.

3 Shah S, Bachur R, Kim D, et al. Lack of predictive value of tachypnea in the diagnosis of pneumonia in children. Pediatr Infect Dis J 2010; 29: 406-409.

4 Durbin WJ, Stille C. Pneumonia. Pediatr Rev 2008; 29: 147-158.

5 Rudan I, Boschi-Pinto C, Biloglav Z, et al. Epidemiology and etiology of childhood pneumonia. Bull World Health Organ 2008; 86: 408-416.

6 Jokinen C, Heiskanen L, Juvonen $\mathrm{H}$, et al. Incidence of communityacquired pneumonia in the population of four municipalities in eastern Finland. Am J Epidemiol 1993; 137: 977-988.

7 Murphy TF, Henderson FW, Clyde WA Jr, et al. Pneumonia: an elevenyear study in a pediatric practise. Am J Epidemiol 1981; 113: 12-21.

8 Heiskanen-Kosma T, Korppi M, Jokinen C, et al. Risk factors for community-acquired pneumonia in children: a population-based case-control study. Scand J Infect Dis 1997; 29: 281-285.

DOI: $10.1183 / 09031936.00164010$

\section{From the authors:}

We would like to thank M. Don for his valuable comments. We disagree, however, with his conclusion that our results [1] were biased because not all community-acquired pneumonia (CAP) diagnoses were confirmed by chest radiograph. As explained in our discussion, our selection of cases reflected daily practice in primary care. Therefore, the external validity of results was better than if we had restricted our analysis to radiographically confirmed CAP. M. Don also criticises us for including nonWestern minorities but not including risk factors that he thinks are relevant in these subgroups, such as malnutrition, low birth weight and measles immunisation. However, non-Western immigrants included in this database were almost exclusively people from Turkish and Moroccan origin in whom these health parameters are not different from the native Dutch population.

Finally, we thank M. Don for pointing out the fact that our findings are in line with the results of the study by HEISKANENKosma et al. [2]. The reason why we did not mention this study was that it almost exclusively included CAP that was confirmed by chest radiograph. Half of the children in the Finnish study were referred to hospital, indicating that they studied a selected subgroup of children with severe lower respiratory disease. However, the fact that our results are in line with their findings supports the validity of both studies.

\section{T. Verheij, J. Teepe and L. Grigoryan}

Julius Center for Health Sciences and Primary Care, University Medical Center Utrecht, Utrecht, The Netherlands.

Correspondence: T. Verheij, Julius Center for Health Sciences and Primary Care, University Medical Center Utrecht, Universiteitsweg 100, 3584 CG Utrecht, The Netherlands. E-mail: Th. J.M.Verheij@UMCUtrecht.nl

Statement of Interest: None declared.

\section{REFERENCES}

1 Teepe J, Grigoryan L, Verheij TJ. Determinants of communityacquired pneumonia in children and young adults in primary care. Eur Respir J 2010; 35: 1113-1117.

2 Heiskanen-Kosma T, Korppi M, Jokinen C, et al. Risk factors for community-acquired pneumonia in children: a population-based case-control study. Scand J Infect Dis 1997; 29: 281-285.

DOI: $10.1183 / 09031936.00171410$ 